\title{
Volatility Distribution of the DJSTOXXE50 Index
}

\author{
Yasemin Ulu ${ }^{1}$ \\ ${ }^{1}$ Department of Economics, The Scott L. Carmona College of Business, Saginaw State University, United States \\ Correspondence: Yasemin Ulu, Department of Economics, The Scott L. Carmona College of Business, Saginaw State \\ University, United States.
}

Received: March 9, 2020

Accepted: October 19, 2020

Available online: November 2, 2020

doi:10.11114/aef.v7i6.5065

URL: https://doi.org/10.11114/aef.v7i6.5065

\begin{abstract}
In this paper using data from 1995-2005 on 5-minute intraday returns, we construct a model free estimate of the daily realized volatility for the DJSTOXXE50 index. We compute the unconditional volatility distribution of the DJSTOXXE50 index by a nonparametric kernel estimation method. Our results indicate that the unconditional volatility distribution of the DJSTOXXE50 returns are leptokurtic and highly skewed to the right. The logarithmic standard deviations seem to be approximately Gaussian. Our results are inline with previous research for individual DJIA equity return volatility and for Japanese index, Nikkei $225^{1}$.
\end{abstract}

Keywords: realized volatility, unconditional empirical volatility distribution, DJSTOXXE50 index, realized stock market volatility

\section{Introduction}

After the availability of high frequency asset price data and the development of realized volatility literature more research is focusing on studying the market microstructure, intraday volatility dynamics and realized volatility of various markets. Relevant to our study, Andersen et. al. (2001a) study the distribution of stock return volatility while, Andersen et. al. (2001b) study the distribution of exchange rate volatility. As pointed out in Bollervslev et. al. (2001), mostly due to limited access to high frequency data, most of these studies concentrate on US equity markets or exchange rate markets with the exception of Andersen et. al (2000a) where they study the intraday and interday volatility dynamics of the Japanese stock market, Nikkei 225. The generalizations of the findings of these studies to global indexes and exchange rate markets is of interest and might provide further insights into high frequency volatility dynamics.

This paper aims to fill this gap by exploring a unique data set of 5-minute returns for a 10 year span for the German DJSTOXXE50 index. German DJSTOXXE50 index is composed of 30 German stocks that have the highest market capitalization and turnover volume among the stocks traded in the Frankfurt Stock Exchange. DJSTOXXE50 index is thought as a counter part of the US DJIA index in that interms of their respective exchanges they represent more than one half of the total market capitalization. Since DJSTOXXE50 index and DJIA are thought to be as similar indices, it is interesting to study the similarities and differences in intraday and interdaily volatility dynamics of the two markets. In this paper, we analyze the behavior of the intraday and interdaily volatility dynamics of the DJSTOXXE50 index, using daily-weekly monthly realized volatilities. We compute the kernel density estimates and analyze the sampling properties of the unconditional variance. This paper is different from the existing studies in that, although there are a few studies on the volatility dynamics of the DJSTOXXE50 index, this is the first study that looks at the intraday and interdaily volatility dynamics using high-frequency data. Secondly, we use realized volatility that lets us treat volatility observed rather than latent.

In the next section we introduce the data, section 3 is on the computation of realized volatilities. Section 4 demonstrates the results. Section 5 concludes.

\section{Data}

We use intra day data sampled at 5 minute frequencies for DJSTOXXE50. High-frequency index data are purchased

\footnotetext{
${ }^{1}$ An early version of the abstract was presented at the 11. International Statistics Congress 2019 04-08 October 2019 Bodrum, Mugla, Turkey.
} 
from Olsen Financial Technologies. The data are filtered for outliers and 5-min prices are generated by linearly interpolating the average of log-bid and log-ask for two closest ticks. We delete the weekends from Friday 21:05 Greenwich Mean Time (GMT) until Sunday 21:05 GMT, holidays, and days of unusually low trading volume. The realized variances are computed using $R V_{t}=\sum_{j=1}^{M} r_{t j}^{2}$ where $r_{t j}^{2}$ denote the continuously compounded within day returns of day t (please see section 3 for more detail) and realized volatility is calculated by the square root of the realized variance. The data runs from 1/2/1995-30/6/2005.

\section{Realized Volatility}

Let the logarithmic price of a financial asset be denoted by $p_{t}$ follow the stochastic volatility process $p_{t}=p_{0}+\int_{0}^{t} \mu(s) d s+\int_{0}^{t} \sigma(s) d W(s)$ where $\mu$ and $\sigma$ are cadlag; $\mathrm{W}$ is a standard Brownian motion and $\sigma$ is assumed to be independent of $\mathrm{W}$. This form of stochastic volatility process is a special type of semi-martingale and used in financial modeling. The quadratic variation process for a sequence of partitions $\tau_{0}=0 \leq \tau_{1} \leq \ldots \ldots \leq \tau_{n}=t$ is defined by

$$
[p]_{t}=p \lim \sum_{j=0}^{n-1}\left(p_{\tau_{j+1}}-p_{\tau_{j}}\right)^{2}
$$

And as $\sup _{j}\left\{\tau_{j+1}-\tau_{j}\right\} \rightarrow 0, n \rightarrow \infty$ the integrated variance is obtained by

$$
[p]_{t}=\int_{0}^{t} \sigma(s) d s
$$

Then the integrated variance can be estimated consistently by sum of intraday squared returns compounded at small intervals [See Andersen and Bollerslev 1998, Andersen et. al (2001), Barndoff-Nielsen, and Shephard (2001)].

Let $\quad r_{t j}=p_{t-1+\frac{j}{M}}-p_{t-1+\frac{j-1}{M}} \quad \mathrm{j}=1, \ldots . ., \mathrm{M}, \quad$ denote the continuously compounded within day returns of day $t$ with sampling frequency $M$, then realized variance for day $t$ can be given by;

$$
R V_{t}=\sum_{j=1}^{M} r_{t j}^{2}
$$

And as $M \rightarrow \infty, \mathrm{RV}_{\mathrm{t}} \rightarrow \int_{t-1}^{t} \sigma^{2}(s) d s$ by theory of quadratic variation of semi martingales. Then the realized volatility is defined as the square root of the daily variance.

\section{Results}

Figure 1 presents the daily-weekly and monthly realized volatilities for the DJSTOXXE50 index. Figure 2. Presents the corresponding sampling properties. We see that all series have comparable means; 0.005961, 0.006141,0.06278. They are all skewed to the right with skewness coefficients; 1.85, 1.48, and 1.132. All three series are leptokurtic with kurtosis values of; 9.982, 5.969, and 4.057. The Jacque-Bera statistics reject normality for all three series. 
Figure 3 presents the kernel density estimates of the daily, weekly and monthly realized volatilities of the DJSTOXXE50 index. The skewness and non-normality is apparent in all three-series.

Figure 4 presents the kernel density estimates of the log-realized daily, weekly, monthly volatilities. Although the JB statistics reject normality we see that they are approximately Gaussian ${ }^{2}$. This result is in line with Andersen et. al. (2001) for individual DJIA equity return volatility and Andersen et. al. (2000b) for Japanese index, Nikkei 225.

\section{Conclusion}

We study the empirical distributional properties of DJSTOXXE50 index. Specifically compute the unconditional volatility distribution of the DJSTOXXE50 index by a nonparametric kernel estimation method. We find that the realized volatility series at all frequencies are skewed to the right, leptokurtic and non-normal. However, the log-realized volatilities appear to be approximately Gaussian. Our results are in line with Andersen et. al (2001) for individual DJIA equity return volatility and Andersen et.al (2000b) for Japanese index, Nikkei 225.
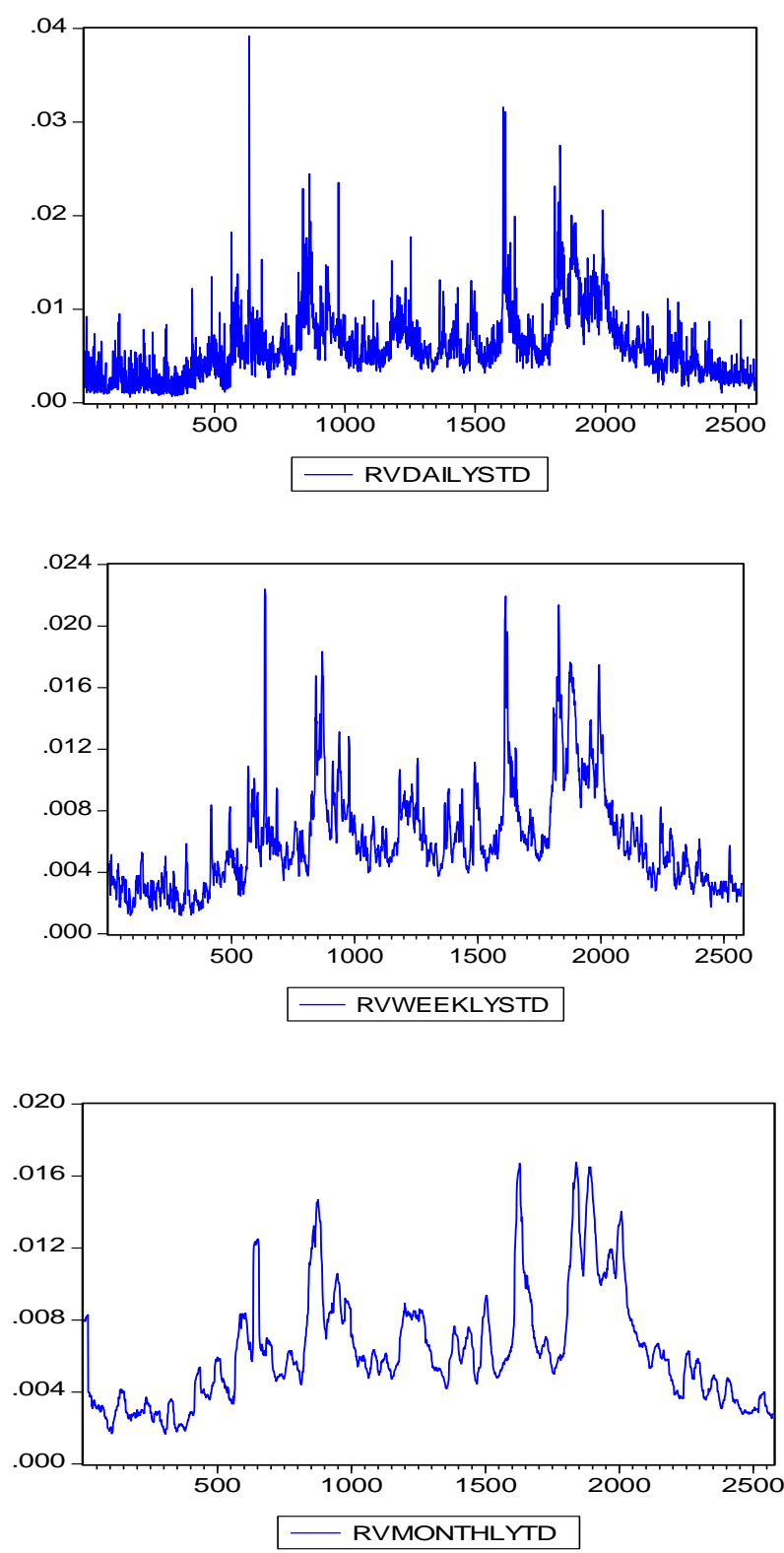

Figure 1. Daily-,weekly-, monthly- realized volaity of DJSTOXXE50 index

\footnotetext{
${ }^{2}$ These results are mitted for brevity and are available upon request.
} 


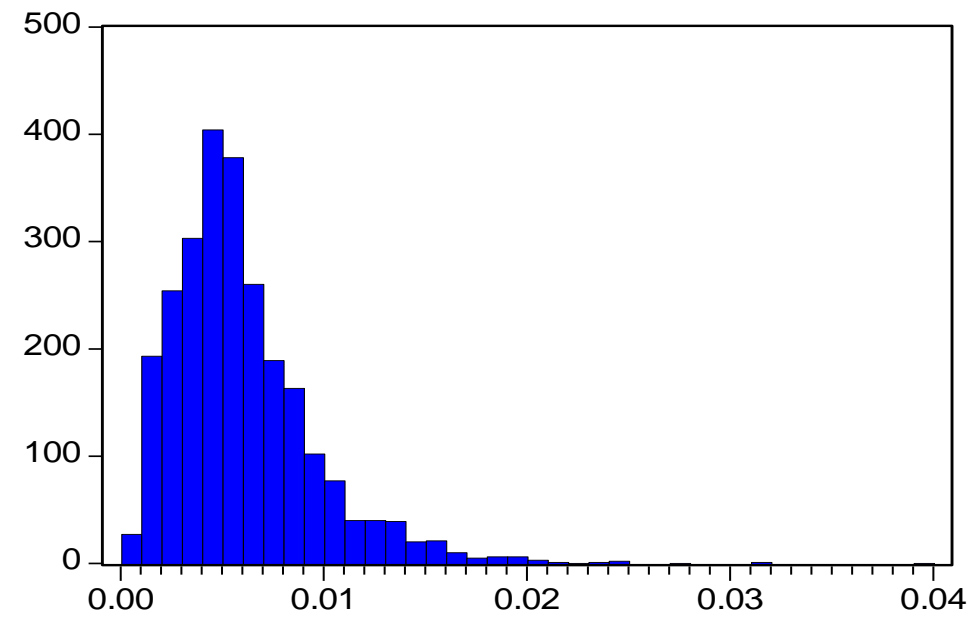

Series: RVDAILYSTD

Sample 12574

Observations 2573

Mean

0.005961

Median

0.005250

Maximum

0.039168

Minimum

0.000599

Std. Dev.

0.003652

Skewness

1.850061

Kurtosis

9.982072

Jarque-Bera

6694.113

Probability

0.000000

Descriptive statistics for weekly- realized volatilty of DJSTOXXE50 index

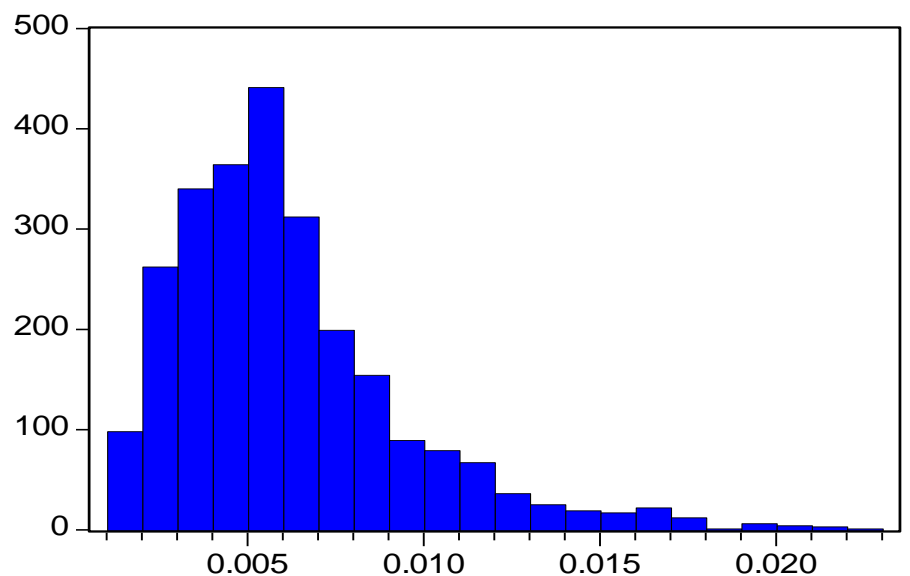

Series: RVWEEKLYSTD

Sample 12574

Observations 2573

Mean $\quad 0.006141$

Median $\quad 0.005454$

Maximum $\quad 0.022391$

Minimum $\quad 0.001190$

Std. Dev. $\quad 0.003344$

Skewness $\quad 1.486832$

Kurtosis $\quad 5.969864$

Jarque-Bera $\quad 1893.597$

Probability $\quad 0.000000$

Descriptive statistics for monthly- realized volatilty of DJSTOXXE50 index

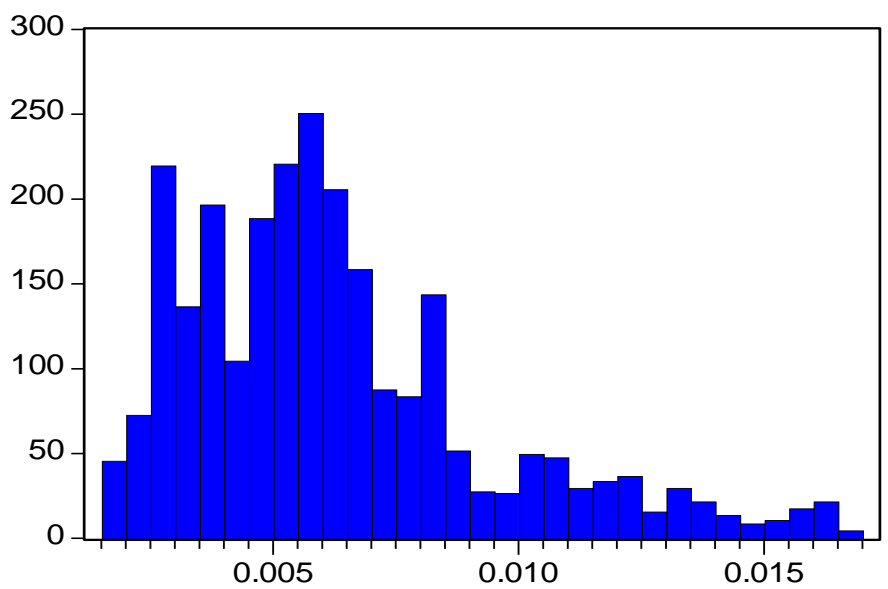

Series: RVMONTHLYTD Sample 12574

Observations 2573

Mean $\quad 0.006278$

Median $\quad 0.005740$

Maximum $\quad 0.016759$

Minimum $\quad 0.001649$

Std. Dev. $\quad 0.003135$

Skewness $\quad 1.132134$

Kurtosis $\quad 4.057159$

Jarque-Bera $\quad 669.4618$

Probability $\quad 0.000000$

Figure 2. Descriptive statistics for daily realized volatilty of DJSTOXXE50 index 

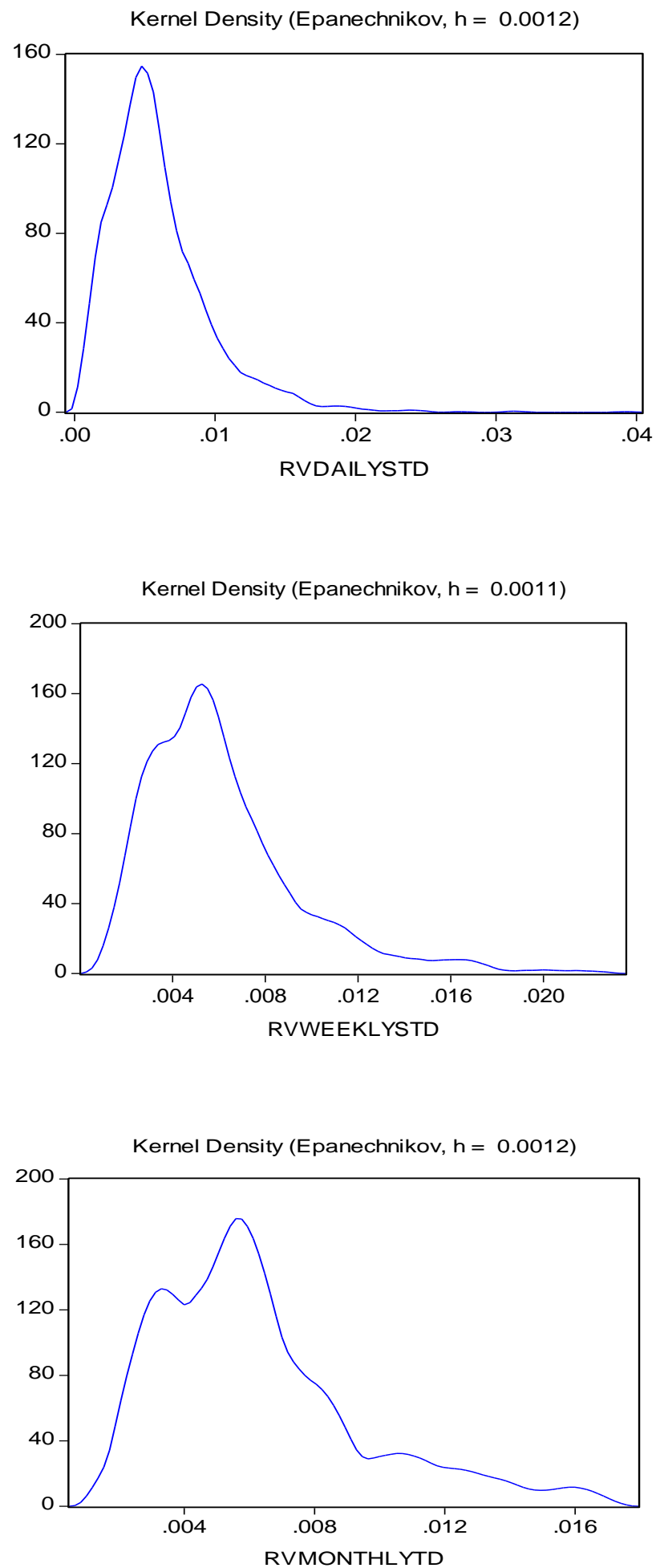

Figure 3. Kernel Density Estimates of the Daily, weekly and monthly realized volatilities of the DJSTOXXE50 index 
Kernel Density (Epanechnikov, $\mathrm{h}=0.2269)$

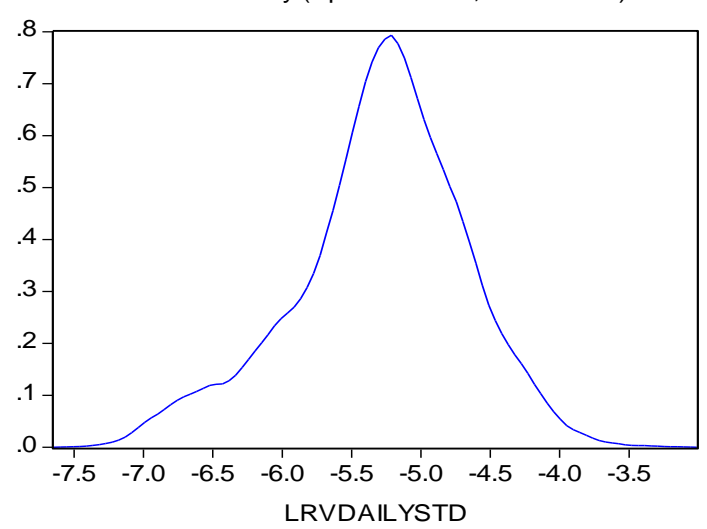

Kernel Density (Epanechnikov, $\mathrm{h}=0.2092$ )
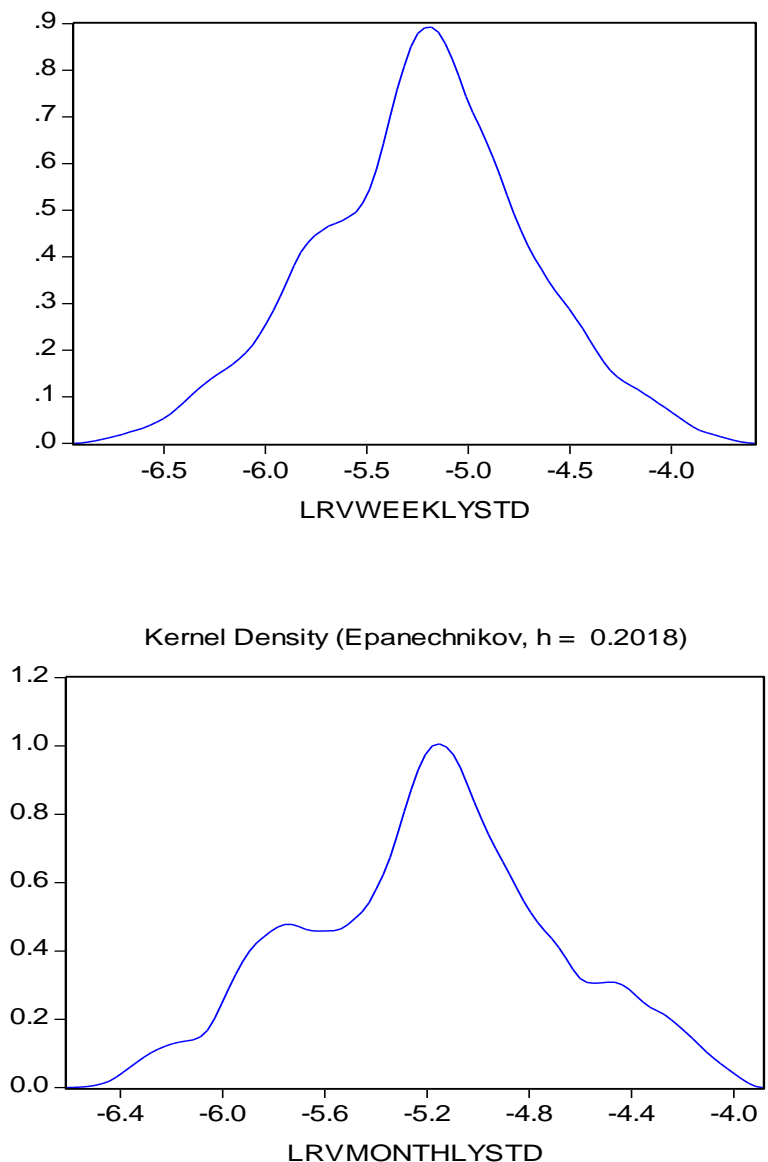

Figure 4. Kernel Density Estimates of the Daily, weekly and monthly log-realized volatilities of the DJSTOXXE50 index

\section{References}

Andersen, T. G., \& Bollerslev, T. (1998). Answering the skeptics: Yes, standard volatility models do provide Accurate Forecasts. International Economic Review, 39, 885-905. https://doi.org/10.2307/2527343

Andersen, T. G., Bollerslev, T., Diebold, F. X., \& Ebens, H. (2001b). The distribution of realized stock return volatility. Journal of Financial Economics, 61(1), 43-76. https://doi.org/10.1016/S0304-405X(01)00055-1

Andersen, T. G., Bollerslev, T., Diebold, F. X., \& Labys, P. (2000a). Exchhange Rate returns standardized by Realized Volatility are (Nearly) Gaussian. Multinational Finance Journal, 4(3-4), 159-179. https://doi.org/10.17578/4-3/4-2 
Andersen, T. G., Bollerslev, T., Diebold, F. X., \& Labys, P. (2001a). The distribution of realized exchange rate volatility. Journal of the American Statistical Association, 96, 42-55. https://doi.org/10.1198/016214501750332965

Andersen, T. G., Bollerslev, T., Diebold, F. X., \& Labys, P. (2003). Modeling and forecasting Realized volatility. Econometrica, 71, 579-625. https://doi.org/10.1111/1468-0262.00418

Andersen, T. G., Bollerslev,T., \& Cai, C. (2000b). Intraday and interday volatility in the Japanese stock market. Journal of International Financial Markets, Institutions and Money, 10, 107-130. https://doi.org/10.1016/S1042-4431(99)00029-3

Barndorff-Nielsen, O. E., \& Shephard, N. (2001). Non-Gaussian Ornstein-Uhlenbeck-based models and some of their uses in financial economics. Journal of the Royal Statistical Society, Series B 63,167-241.

https://doi.org/10.1111/1467-9868.00282

\section{Copyrights}

Copyright for this article is retained by the author(s), with first publication rights granted to the journal.

This is an open-access article distributed under the terms and conditions of the Creative Commons Attribution license which permits unrestricted use, distribution, and reproduction in any medium, provided the original work is properly cited. 